\title{
TUBA1B Antibody
}

National Cancer Institute

\section{Source}

National Cancer Institute. TUBA1B Antibody. NCI Thesaurus. Code C115148.

Any immunoglobulin that recognizes tubulin alpha-1B chain protein. 